Journal of Systemic Therapies, Vol. 25, No. 2, 2006, pp. 80-94

\title{
INCORPORATING NATURE INTO THERAPY: A FRAMEWORK FOR PRACTICE
}

\author{
RONEN BERGER \\ The Nature Therapy Centre, Tel-Hai Academic College, Israel \\ JOHN MCLEOD \\ Tayside Institute for Health Studies, \\ University of Abertay Dundee, Scotland
}

\begin{abstract}
In most cases, therapy is addressed as an indoor, verbal, and cognitive activity, with the relationship between therapist and client at its center (McLeod, 2003). This article presents an alternative approach to therapy, conducted in creative ways in nature, addressing the environment not merely as a setting but as a partner in the process. The article includes examples of work that took place with different clients, in varied settings. It aims at presenting basic concepts from this young framework that will inspire other practitioners to "open the doors" and explore these ideas with their clients in nature.
\end{abstract}

The concept of conducting transformative and healing work in nature is not new; it can be traced back to ancient times when people lived in communities in nature. In those days, shamans would incorporate nature's healing powers into the performance of rituals and into the overall framework of traditional medicine. These rituals, which can be viewed as an ancient form of therapy (Al-Krena, 1999; Grainer, 1995; Jennings, 1995; Jerome, 1993; Jones, 1996; Pendzik, 1994; West, 2004), were used to help people recover from illness, cope with the unknown, and make the transition from one status to another (Eliade, 1959; Evans, 1997; Hazan, 1992; Jennings, 1995; Meged, 1998; Turner, 1986).

After the scientific revolution and the development of modern therapy, Erickson, one of Freud's leading students and an important theoretician in his own right, used the experiential encounter with nature not only for his own healing but also for his clients; he would send them to the mountains as part of the process (Kinder, 2002). Years later, adventure therapy was developed by working outdoors with youth and adults having difficulties coping with boundaries and with authority (Garst, Scheider, \& Baker, 2001; Kaly \& Hessacker, 2003; Neill \& Heubeck, 1998;

Address correspondence to Ronen Berger, Kibbutz Kfar Giladi 12210, Israel. E-mail: ronenbw@hotmail .com. 
Price \& DeBever, 1998; Simpson \& Gillis, 1998). It was also used in caring for children with special needs, families, anorexic women, and people suffering from psychiatric illness (Bandoroff, 2003; Burg, 2001; Crisp \& O'Donnell, 1998; Richards, Peel, Smith, \& Owen, 2001; Roberts, Horwood, Aunger, \& Wong, 1998). Adventure therapy usually approaches nature as a setting (location) and as a provider of challenges in what constitutes a concrete and task-oriented process (Beringer \& Martin, 2003; Itin, 1998; Richards \& Smith, 2003; Ringer, 2003). In most cases adventure therapy does not emphasize the emotional, metaphysical, and spiritual aspects of nature (Berger, 2003; Beringer \& Martin, 2003).

In recent years, however, due to the negative effects of some aspects of technological development upon various social and environmental processes, the relationship between human beings and nature has received more and more recognition (Roszak, 2001; Roszak, Gomes, \& Kanner, 1995; Totton, 2003). Many writers have suggested that the rupture between human communities and the natural world contributes to a lack of psychological well-being and ultimately to emotional problems and ill-health (Kuhn, 2001; Pilisuk \& Joy, 2001; Roszak, 2001; Roszak et al., 1995). The growing field of eco-psychology reflects this attitude in its developing social-therapeutic-environmental philosophy, claiming that reconnection with nature is essential not only for the maintenance of the physical world (habitats, animals, plants, landscape, and cultures) but also for people's well-being and happiness (Roszak, 2001; Roszak et al., 1995; Totton, 2003). Many writers have written about the therapeutic aspects of nature and contact with nature (Abram, 1996; Berger, 2004; Beringer \& Martin, 2003; Davis, 1998; Naor, 1999; Roszak, 2001; Totton, 2003). Few have tried to reconstruct the knowledge gained through practice and intuition into creating a therapeutic framework using the relationship with nature as the key reference point for therapy.

\section{NATURE THERAPY: DEVELOPING A FRAMEWORK FOR PRACTICE}

Within therapeutic practice, a nature-informed approach has been employed as a specific model of therapy, titled nature therapy (Berger, 2003, 2004, 2005), and as a source of concepts and practices that can be integrated into any therapeutic model. Nature therapy broadens the classical concept of "setting" as static, permanent, and under the control and ownership of the therapist (Barkan, 2002; Bleger, 1967). Rather, nature therapy relates to the environment as a live and dynamic partner in the shaping of the setting and the process (Berger, 2004). Nature therapy develops concepts and methods that assist its operation in nature, while addressing ways that the unique characteristics of this independent environment not only can influence the therapeutic act but also can be used by the therapist to open it up to additional dimensions. Nature therapy is a postmodern experiential approach based on the integration of elements from art and drama therapy, Gestalt, 
narrative, eco-psychology, transpersonal psychology, adventure therapy, shamanism, and body-mind practices. The approach was developed in the doctoral program of the first author of this article, under the supervision of the second author. It has been implemented with individuals, groups, and families in the private, educational, and health sectors in Israel. Training is provided in a few academic institutions in Israel and currently developing in Europe.

The aim of this paper is to examine some of the core principles involved in incorporating a relationship with nature as the key reference point in constructing and developing a therapeutic process. We use case studies that highlight the theory to illustrate ways it can be used with different clients and in different settings. All of the examples used in the article have been implemented by the first author of the article, during his work with Jewish clients living in Israel.

\section{NATURE AS A THERAPEUTIC SETTING}

One of the basic concepts of nature therapy relates to the issue of nature as a therapeutic setting. Nature is a live and dynamic environment that is not under the control or ownership of either therapist or client. It is an open and independent space, which has existed before their arrival in it and will remain long after they depart from it (Berger, 2003). This characteristic is quite different from an indoor setting which is usually owned by the therapist who has furnished it for the purpose of seeing clients and doing therapy (Barkan, 2002). Choosing to relate to nature as a place in which to conduct therapy prods the therapist into relating to these issues and creating a framework that will not only take these characteristics into account but will incorporate them into the therapist's therapeutic rationale. The building-a-home-in-nature method (Berger, 2004) implements the concept of nature as a therapeutic setting in a concrete embodied way, addressing it as a key point of reference in an essentially nonverbal therapeutic process.

Joseph was a 12-year-old boy whose life was complicated by communication problems and social difficulties. From the onset of therapy, which took place at the school he attended for children with special needs, Joseph made it clear that he was not comfortable in the counseling room. Instead, he invited his therapist for walks near his classroom. In time, the boundaries of these walks expanded from inside the well-known area of the institution to a nearby, yet unfamiliar, riverbank. As time went by, the boy chose a specific place on the riverbank, under a willow tree, hidden from passers-by. As the therapeutic goal of these sessions was to help Joseph expand his social and communication skills, the encounters began with concrete actions such as brewing tea over a fire. As time progressed, it became evident that he was paying careful attention to maintaining the exact location, manner, and order of the activities. In addition, it became clear that he was busily collecting sticks and stones from the riverbank to construct a small 
barrier around the area in which the "tea ceremony" took place, making sure it was performed precisely in the center. Little by little a relationship between Joseph and his therapist was created through the construction of the barrier, the direct physical encounter in nature, and the repetition of activities and ceremonies conducted in a specific place. A crucial turning point occurred when the construction of the barrier surrounding the "tea place" was completed. Joseph dramatically expanded his use of language and his desire to connect with the therapist and to tell his own story. Later on, as winter began, sessions moved indoors to the clinic and the work continued through story making and drawing. When difficult, conflict-riddled situations arose, Joseph would once again lead his therapist to the place on the riverbank, which by then had been named the "Home-in-Nature." It was as though Joseph needed to check that the safe sacred space that he and his therapist had physically built together, a space that also symbolized their therapeutic alliance, was still there. It seemed like he wanted to see what had changed during the season and what needed to be reconstructed.

\section{Choosing and Maintaining Therapeutic Space}

In Joseph's story, the process of choosing a location and later building a home-innature was central to his therapy. The process began from the therapist's allowing Joseph to take authority over the physical location of the encounters, inviting Joseph to choose not only what to do with the location but also where it would be. This choice allowed Joseph to set out from the familiar educational territory of the school to a distant riverbank, where he could encounter and construct a personal therapeutic space. On the site of his choice, Joseph picked a hidden place under a willow tree in which he created a circle of stones, forming a separate, enclosed territory in which fire could be made, relationships built, and stories told. In this respect, building a home-in-nature relates to the ancient concept of "sacred space." This concept goes back to the beginning of civilization and can be found in most cultures. Its main function in shamanistic and traditional medicine was to create a space that was protected from the intrusion of evil forces (spirits) and to allow the performances of transformative rituals. In this respect "sacred spaces" can be addressed as healing space par excellence (Eliade, 1959; Pendzik, 1994; Turner, 1986). This example illustrates the potential that lies in the very action of choosing and maintaining the therapeutic space. This is a key concept that can be implemented in any form of therapy, especially those forms that take into consideration the issue of space and the option of working outside clinic settings.

\section{Working in the Intermediate Zone: Between Fantasy and Reality}

The concept of working in an environment which is qualitatively different from that of one's ordinary "everyday" rests on the basic drama therapy concepts of working in the "as if reality" (Jennings, 1998; Lanndy, 1996). This concept seeks to 
use this distancing to allow participants to experience roles and situations which might be difficult for them to cope with in the everyday life. In this aspect, the building-a-home-in-nature method helps to link the fantasy world with the concrete world by extending the isolated and protected "laboratory space" of the clinic into the "real" and less controlled natural world. Conscious transition between the two spaces can help a person explore the gap between the home he or she imagined and the home he or she really lives in. This knowledge can be transferred back and forth, addressing the changes nature makes (in the home-in-nature) as a chance to address the unexpected and uncontrollable. In this aspect, the concepts of "between the spaces" can be used to help a person integrate fantasy and the concrete, the things he or she dreams of and wishes for in his or her everyday "real" life.

\section{Building a Home-in-Nature: A Practical Method}

As choosing, constructing, and maintaining therapeutic space are key elements in nature-informed therapy, the activity of building a home-in-nature can be used as a nonverbal method to invoke a wide range of issues, such as the location of the home, what it contains, the materials used to build it, its state of permanence or mobility, the nature of its borders, and so on. This intervention invites the client to reflect on the qualities of the home in the city where the person has spent his or her life. On a more profound level it probes the question of whether the person feels he or she has or does not have a sufficiently secure base, a coherent sense of self or a sense of definitive boundaries (Berger, 2004). Another important aspect of the concept of nature as a therapeutic setting, which is directly implemented in the building a home-in-nature method, refers to the therapist's standpoint as it relates to issues such as hierarchies and responsibility. This attitude relates to White and Epston's narrative ideas and to some Gestalt principles (Freedman \& Combs, 1996; Kepner, 1987; White \& Epston, 1990), inviting the therapist to flatten hierarchies as he or she takes part in physically constructing the site of encounter together with the client. This approach can be used to beckon the client to shoulder responsibility and ownership over the client's own process as well as for the creation of the therapeutic alliance. This concrete doing can be used to send a message about the options that the client has of reconstructing reality from elements that can be found in the here and now, expanding personal narratives and life possibilities.

\section{INCORPORATING NATURE IN THE CREATION OF RITUALS}

One of the central principles underlying nature therapy is the intentional creation of rituals. This mode of working relates to times when people lived in communities in nature. In those days, life was powerfully connected to nature, as people 
depended directly on it for their physical, social, and spiritual existence. The attitude toward life was embedded in a strong sense of collectivity: the individual was part of a family, which was part of the tribe, which was part of nature, which was part of the universe. Each of these elements was connected to, embedded in, and interdependent on the other. A change in one spelled a change in all (Eliade, 1959; Meged, 1998; Turner, 1986). Religion was central to the maintenance of these communities as it anchored beliefs and held moral and social systems in place (Hazan, 1992; Meged, 1998; Turner, 1986). Rituals played a strong role and were extremely important in giving people a sense of order and security, fostering a feeling of togetherness and providing a sense of control over the uncertainties of life. Ritual also had an essential social function in helping individuals move from one social stage to another (Eliade, 1959; Evans, 1997; Hazan, 1992; Jennings, 1995; Meged, 1998; Turner, 1986). The shaman was the person responsible for the performance of these rituals, which not only aimed at helping individuals and the group but also were important in protecting values, beliefs, and the lifestyles of the entire collective (Eliade, 1959; Meged, 1998). In this sense the shaman can be viewed as an ancient form of therapist (Grainer, 1995; Jennings, 1995, 1998; Jones, 1996; West, 2000).

\section{Seeking Integration in a World of Many Choices}

In the current urban, scientific, secular, and individualistic society we live in, it appears that we deal with the same basic and universal issues that faced our predecessors, though rituals are losing their function as verbal therapy takes the place of religion (Jerome, 1993; McLeod, 1997). Many have written about the important role that ritual plays in modern therapy and about ways in which traditional ceremonies can be incorporated therein (Al-Krena, 1999; Grainer, 1995; Jennings, 1995, 1998; Jerome, 1993; Jones, 1996; West, 2000, 2004). Several disciplines, such as drama therapy, even relate to shamanic rituals as their precursor as they adjust the principles of performance and the concept of the sacred space into their framework (Grainger, 1995; Jennings, 1998; Jones, 1996; Pendzik, 1994). Despite the existing option of performing traditional rituals in therapy groups, it would appear that the secular, multicultural, and individualistic background which most clients come from do not necessarily include a religious, spiritual, or ritualistic basis that can provide a common ground for their conduct in therapy. Furthermore, there are not necessarily the common symbolic language and belief systems essential for the creation of rituals within multicultural and multineeds groups (Meged, 1998; Moore \& Myerhoff, 1997; Turner, 1967, 1986). In fact, with the growing concept of individualism and variegated lifestyles present in the postmodern decade, it is no longer abundantly clear what kind of "higher truths" or values can bring people together in general and a group of clients in particular. Many writers have written about the challenges that this poses in the postmodern 
therapeutic arena, which must provide a space that can hold different parts of the personality and prevent the development of a "fragmented or saturated self" (Gergen, 1991; McLeod, 1997; West, 2000). Therefore, at a time of separation between religious rituals and therapy, or when many people find it difficult to relate to rituals on a spiritual and emotionally transformative level (West, 2000), what should be the place of the therapist in providing a space for the creation of (secular) rituals? In what ways can the relationship with nature assist this process?

A training workshop took place on a full moon's night on the beach. It was the last encounter of a group that had participated in nature therapy postgraduate training. The workshop began several hours before sunset and continued on throughout the night. After midnight, as the group shared personal stories around the fire, David, a man in his late twenties, shared his reflections about the year's process. He expressed appreciation that it had helped him separate from his parents and move into a new home with his girlfriend. As dawn rose, several hours later, participants were asked to set off on individual journeys, picturing each step in the sand like a step in their lives. An hour later, upon their return, they were asked to pick a space on the beach and create a figure or statue in the sand that symbolized the process they had gone through during the year's training. Using his body, David dug two funnel-shaped channels in the sand at the dividing line between the sand and the water. The narrow side of the funnel was directed at the sunrise while its wide side faced the sea. As the group traveled between the personal spaces witnessing people's work and developing their stories, David invited the group to gather around his creation. "Before, when I was playing with the sand I had no idea what I was constructing; now that I am standing here with you it seems to be some kind of a birth canal." Accepting the therapist's invitation to undergo a spontaneous (made-up) ritual, David removed his shirt and sat down at the entrance of the funnel as the other participants formed a tight human canal around the channel in the sand. Minutes later, amidst much pushing, shouting, and crawling David made his way out of the narrow channels into the open beach. A few seconds later, lying breathless on the sand, a big wave washed him from behind. "I am alive," he shouted, "reborn." The participants gathered around him in group, wrapping his wet body with blankets as spontaneous songs emerged; lullabies and birthday songs, and prayers mingled with tears and laughter.

\section{Working with Universal Truth}

The above example begins with the therapist's choice of conducting a separation workshop on the seashore, under moonlight. This choice of the liminal time between sunset and sunrise matched his desire to induce separation and birth stories and to nurture group members into making the transition from students to counselors. The choice of setting is related to the concept of the universal truth inher- 
ent in the cycles of nature that can connect people to the large cycle we are all part of: the cycle of life and death, past, present, and future (Berger, 2005, 2006). In this sense, the cycle of sunset and sunrise, high and low tide can be used as collective symbols of the cycle of life and death. This not only allows complex stories to be told, it can also normalize them as they are present in the cycles of all living beings.

\section{Working with the Concept of Therapy as a Journey}

This approach is based on the belief that a conscious physical journey in nature can trigger parallel psychological and spiritual quests that can open a channel for mind-body work. In this respect, each part of the nature - the landscape, the elements, the weather, animals, and so forth-has a specific resonance on the client, inviting the client into an inner process.

In David's story, this concept was used by the facilitator who asked participants to set off for individual journeys on the beach. Upon their return, they were asked to embody the metaphors, stories, sensations, and feelings they had encountered on the sand. Then, correlating David's story (which was not new for the facilitator and group), the concrete metaphor of the birth canal and the figure he had created on the beach, the idea for the ritual was created and later performed. A cathartic experience occurred with the breaking wave, which completed the ritual and further expanded its entire meaning. This example not only presents the way in which an encounter with nature can address universal truth and act as a bridge between people, but also shows the way that an uncontrollable (yet not totally surprising) natural element can be incorporated into the creation of rituals, sending a message about people's ability to engage in dialogue with the uncontrollable. In this sense, nature therapy's rituals resemble shamanic rituals. They take account of nature as active participants in their making. They also utilize nature as a nonhuman medium that can help people bestow meaning and help guide them through change.

\section{USING NATURE AS A SOURCE TO RECONNECT BODY, SPIRIT, AND MIND}

Another key concept is expanding the therapist-client therapeutic relationship by the addition of nature as a third party. As such, this concept is designed to help the therapist relate to nature as an active partner (perhaps a kind of co-therapist), influencing not only the setting, but the entire therapeutic process (Berger, 2004, 2005). In relation to this concept, the therapist is encouraged to develop a specific standpoint. The therapist may take a central position, working directly with the client and relating to nature as a backdrop or tool provider. The therapist may 
also take a quieter role, remaining in the background, allowing the client to work directly with nature while the therapist acts as a witness, container, and mediator.

Ran, a man in his mid-30s, a successful and busy health professional, was experiencing difficulties in coping with the stresses of a demanding career combined with family needs. He developed intestinal symptoms that could not be controlled by medical treatment and turned to psychotherapy. During his first two sessions with his therapist, Ran described his stomach as a "hot, wet sponge" which was "not so nice to touch." Asked to say more, he described the exact location of his physical symptoms as "wet soil," quite revolting and unpleasant to be in. He said that when he had been in counseling in the past, he had always stopped when talk of this "soil" became intense. "I avoid that place at all costs; it feels like I am being invaded." Seeking a way to bypass this verbal obstacle, the therapist asked Ran if he would be interested in experiencing some real wet soil and offered to conduct the work in nature. After Ran agreed to try out this idea they spent the next sessions at a quiet place by the riverbank. The therapist invited Ran to take his time and get to know the ground as he remained in the background as a silent witness. Then he encouraged him to explore the sensations of the dry warm sand by digging his hands into it. Later, Ran moved toward the river and began to play with the wet sand and the mud. At first he hated touching the stuff, but as the seasons changed he relaxed and even began to enjoy the childlike appeal of this activity and the spontaneous play in the mud. Sessions were held at the end of day; a time when daylight was shifting into darkness and the voices of morning animals were changing into night voices. As Ran found a place where he felt safe enough to touch and enter the "wet soil" he began to talk about painful memories from his childhood and about the ways they were impacting his relationship with his children today. Then, staying attentive to the way the voices and sights of nature changed, he began to reflect upon the ways he could relate to these early memories as an adult and father, turning the vulnerability of the child he has been into the strength of the father he is now. Several months later Ran came to therapy accompanied by his two young children. In the first session that took place on the same riverbank he said, "It was through the spontaneous play on the riverbank that I understood just how much I miss my childhood and how much my kids miss me. Nature helped me to reconnect to myself, to appreciate the value of 'non-doing time.' Now I hope it will help me to reconnect to my kids."

\section{Working within the Three-Way Relationship: Client-Therapist-Nature}

The example given illuminates the way in which the Three-way relationship of client-therapist-nature can be utilized to expand a person's patterns and help him 
or her reconnect to his or her body, spirit, mind, creativity, and authenticity. The example illustrates the unique standpoint taken by the therapist as he chose to shift attention from the person-to-person (therapist-client) relationship to the clientnature relationship, remaining the mediator between them. It also highlights the therapist's identification of the benefit this concept can have for the specific client, working with the image that was given verbally by the client in sessions in the indoors clinic and extending its embodied and creative use in nature. Once the client "had sufficient play time" without the interruption of an adult (the therapist), a shift within the "triangle" was made. Painful memories and relationship difficulties could then emerge, unfold, and be discussed within the interpersonal relationship.

\section{TOUCHING NATURE-TOUCHING THE SOUL}

A direct encounter with natural elements can trigger strong emotions and sensations that were not previously touched or shared (Berger, 2004, 2005). The concept of touching nature is based on the belief that through direct physical, emotional, and spiritual encounter with nature one can touch upon deep parts of one's personality, receive profound insights, and sense a strong connection to the universe. This opportunity can help a person to develop qualities which might otherwise be difficult to access in an intensely modern lifestyle (Berger, 2004, 2005).

\section{Using Therapy to Reconnect People and Nature}

This article began with an eco-psychological saying relating to the importance of the equilibrium between people and nature. It claimed that the rupture between the two contributes to a lack of personal well-being as well as the destruction of natural habitats and landscapes. Neass and other eco-physiologists who adhere to the Deep Ecology movement claim that this attitude toward nature stands up to the modern capitalistic lifestyle in which the individual is perceived as a separate entity and not as part of a larger creation (Seed, Macy, Fleming, \& Naess, 1988; Totton, 2003). Relating to this standpoint, it seems that nature therapy joins ecopsychology's philosophy as it offers a practical framework that can help reconnect people and nature and hone the importance of this ancient human-nature alliance.

\section{Finding Personal Meaning through Engaging the Natural Environment}

Traditionally, psychotherapeutic discourse makes it seem as if the therapeutic process takes place in a vacuum. There is hardly any reference to the environment in which the process occurs (Pendzik, 1994). Over the last few decades, with 
the emergence of environmental psychology and other postmodern disciplines, more and more writers have became aware of the different influences that the environment has upon therapist-client transactions (Hall, 1976; Lecomte \& Pendzik, 1996). It has become increasingly evident that the aesthetics of the surroundings affect the person's display of emotions (Maslow \& Mintz, 1956) as well as an individual's social behavior (Barker, 1976; Hall, 1976; Orzek, 1987; Pendzik, 1994). Yet much of this evidence relates to indoor settings in urban environments, mainly built and controlled by human hands. This characteristic of nature-informed therapy may provide yet another powerful element as it broadens the perspective of the relationship with space and opens that relationship up to a much larger cosmic dialogue.

Linda, in her forties, attended a three-day, nature-based therapy group. At the first session of the group, which took place in an indoor setting, near the river, participants were invited to construct an imaginary story that expressed the personal issues, needs, and wishes they had brought to the group. Linda spun a story about a lonely starfish living in the ocean with a soul mate that accompanied him in the sky. The second day of the workshop began with a silent, meditative walk along the river. On arriving at a narrow bridge crossing the river, participants were asked to find a physical element from the surroundings that symbolized a sensation, feeling, or thought from which they would like to depart, say something about it, and throw it into the river. At this point, which produced strong feelings for most group members, Linda shared her grief with losing a loved one with the group. After crossing the bridge, the group arrived at a peaceful and quiet part of the river, where they were invited to create a representation of the story they had told the previous day as a sculpture, picture, or drama using natural elements. Linda created a sculpture in the space on the banks of the river where the water meets the shore. She gathered colorful flowers and placed them on two stones, which she later connected with a stick. She named her sculpture "the couple." The following day, on returning to the same location, Linda was surprised to discover that the live flowers she had picked and used to create her sculpture had dried out and "lost their joy." The change created by nature allowed Linda to connect with her feelings of grief and reflect on her current family relationships. This observation made her realize that perhaps she was grieving not only for the one who had gone but also for those meaningful aspects of her marriage that were in need of revival. Returning to the sculpture on the third day expanded Linda's perspective even further by drawing her attention to the clear running water flowing constantly around her creation and to the changing colors of the surrounding river. This simple intervention enacted at a time of grief helped Linda connect to concepts of continuity and cycling. She was able to realize that her story is part of a much larger cosmic tale. This nonverbal dialogue between Linda and the river filled her with hope. She said that it was allowing her to return home a stronger person, taking "some clean, running water" back to her family. 


\section{Working with the Renewing Environment to Reconnect Personal Strength and Hope}

This example illustrates the way in which the connection between a client's story of grief and loss embedded in a larger natural story of life can help the client extract new meanings out of a difficult episode and study his or her story from additional perspectives. In addition to this strength and narrative attitude that can be found in most postmodern approaches (Freedman \& Combs, 1996, Jennings, 1998; Lahad, 1992; Lanndy, 1996; Rubin, 1984; White \& Epston, 1990), the story also highlights the way in which working with a renewing environment can help a person regain hope and engage their sense of the capacity to make changes in life. Another powerful element of this work, also touched upon in the previous examples, relates to transpersonal and spiritual dimensions (Davis, 1998; Taylor, 1992). Connecting personal and universal cycles can help a person get in touch with his or her larger self and explore dimensions which extend far beyond the person-to-person relationship.

\section{CONCLUSIONS: PROVISIONS FOR A JOURNEY}

The article has presented the insistence of nature therapy on viewing and addressing the client as part of a macrocosm; in relation not only with his or her inner self but also with other people, cultures, landscapes, animals, and plants. In so doing, this article has illustrated an alternative approach to systemic therapies involving the incorporation of nature into the therapeutic alliance. In this sense nature-informed therapy can allow the therapeutic encounter to work as a vehicle for engendering ecological or nature conservation awareness and expand individual points of view to encompass social and collective perspectives. This article has also illustrated a way in which the incorporation of nature into therapy can expand verbal and cognitive modes of working, diminish hierarchies, and help the clients widen their mind-body connection.

At the present time there is very little research evidence concerning nature therapy and only a few training programs. We are currently involved in carrying out research to evaluate the effectiveness of therapeutic and educational programs with different populations in various natural settings and to explore the issues involved in designing further professional training. In developing this approach, our basic assumptions are that nature contains resources that can support emotional, spiritual, mental, and physical personal well-being, which in turn can be used for psychotherapeutic purposes. We believe that the intentional use of nature as a resource can be effectively integrated into any kind of population that seeks therapy. Our hope is that as more of our colleagues develop and disseminate their own ways of conducting therapy in nature, a broader set of case examples and research studies will emerge and subsequently 
a more completely articulated theoretical framework can be constructed and presented.

\section{REFERENCES}

Abram, D. (1996). The spell of the sensuous. New York: Vintage Books.

Al-Krena, A. W. (1999). An overview of rituals in western therapies and interventions: Argument of their use in cross-cultural therapy. International Journal for the Advancement of Counseling, 21(1), 3-17

Bandoroff, S. (2003). Family therapy with a twist and shake and a shout: Adventure family therapy in practice. In K. Richards and B. Smith (Eds.), Therapy within adventure (pp. 243-251). Augsburg, Germany: Ziel Publications.

Barkan, A. (2002). Different faces of the setting. Sihot-dialogue, The Israel Journal of Psychotherapy, 17(1), 39-46. (Hebrew).

Barker, R. (1976). On the nature of the environment. In H. Proshansky, W. Itteison, \& L. Rivlin (Eds.), Environmental psychology. New York: Rinehart \& Winston.

Berger, R. (2003). In the footsteps of nature. Horizons, 22, 27-32.

Berger, R. (2004). Therapeutic aspects of nature therapy. Therapy through the Arts-The Journal of the Israeli Association of Creative and Expressive Therapies, 3, 60-69. (Hebrew).

Berger, R. (2005). Nature therapy with elderly people. Generations, 80, 37-38.

Berger, R. (2006). Between the circle and the cycle: A multi-dimensional exploration into a nature therapy training. Israel: The Nature Therapy Center Press.

Beringer, A., \& Martin, P. (2003). On adventure therapy and the natural worlds: Respecting nature's healing. Journal of Adventure Education and Outdoors Learning, 3, 29-40.

Bleger, J. (1967). Psycho-analysis of the psychoanalytic frame. International Journal of Psychoanalysis, 48, 511-519.

Burg, J. E. (2001). Emerging issues in therapeutic adventure with families. Journal of Experiential Education, 24(2), 118-223.

Burns, G. A. (1998). Nature-guided therapy: Brief intervention strategies for health and well-being. London: Taylor and Francis.

Crisp, S., \& O’Donnell, M. (1998). Wilderness adventure therapy in adolescent psychiatry. In C. M. Itin (Ed.), Exploring the Boundaries of adventure therapy: International perspectives (pp. 346-359). Boulder, CO: Association of Experiential Education.

Davis, J. (1998). The transpersonal dimensions of eco-psychology: Nature, nonduality, and spiritual practice. The Humanistic Psychologist, 26(1-3), 60-100.

Eliade, M. (1959). The sacred and the profane. New York: Harcourt Brace Jovanovich.

Evans, J. R. (1997). Passages of the soul. Dorset, England: Element Books.

Freedman, J., \& Combs, G. (1996). Narrative therapy: The social construction of preferred realities. New York: W. W. Norton \& Company.

Garst, B., Scheider, I., \& Baker, D. (2001). Outdoor adventure program participation impacts on adolescent self-perception. Journal of Experiential Education, 24(1), 41-50. 
Gergen, K. J. (1991). The shattered self: Dilemmas of identity in modern life. New York: Basic Books.

Gillis, H. L., \& Ringer, M. (1999). Adventure as therapy. In J. C. Miles \& S. Priest (Eds.), Adventure programming. State College, PA: Venture Publishing.

Grainer, R. (1995). The glass of heaven. London \& Bristol, England: Jessica Kingsley Publishers.

Hall, E. (1976). The anthropology of space: An organizing model. In H. Proshansky, W. Itteison, \& L. Rivlin (Eds.), Environmental psychology. New York: Rinehart \& Winston.

Hazan, H. (1992). The anthropological discourse. Tel Aviv, Israel: The Ministry of Defense.

Hazut, T., \& Segev-Shoham, E. (2004). The power of creation in "The work of hope." Therapy through the Arts, 3(2), 27-44.

Itin, C. M. (Ed.). (1998). Exploring the boundaries of adventure therapy: International perspectives. Proceedings of the 1st International Adventure Therapy Conference. USA: Association of Experiential Education.

Jennings, S. (1995). Theatre, ritual and transformation. London: Routledge.

Jennings, S. (1998). Introduction to drama therapy. London: Jessica Kingsley Publishers.

Jerome, D. F. (1993). Persuasion \& healing. New York: Schocken Books.

Jones, P. (1996). Drama as therapy, theater as living. London: Routledge.

Kaly, P. W., \& Hessacker, M. (2003). Effects of a ship-based adventure program on adolescent self-esteem and ego-identity development. Journal of Experiential Education, 26(2), 97-105.

Kepner, J. I. (1987). Body process: A gestalt approach to working with the body in psychotherapy. New York: Gestalt Institute of Cleveland Press.

Kinder, D. W. (2002). Nature and psyche: Radical environmentalism and the politics of subjectivity. Albany, New York: State University of New York.

Kuhn, J. L. (2001). Towards an ecological humanistic psychology. Journal of Humanistic Psychology, 41, 9-24.

Lahad, M. (1992). Story-making as an assessment method for coping with stress six-piece story-making and BASIC Ph. In S. Jennings (Ed.), Drama-therapy theory and practice 2. London: Routledge.

Lahad, D. (2002). Creative supervision. London: Jessica Kingsley Publishers.

Lanndy, R. J. (1996). Essays in drama therapy. London: Jessica Kingsley Publishers.

Lecomte, C., Berstin, B., \& Dumont, F. (1981). Counseling interactions as a function of spatial-environment conditions. Journal of Counseling Psychology, 28, 536-529.

Maslow, A., \& Mintz, L. (1956). Effects of aesthetic surroundings. The Journal of Psychology, 41, 247-254.

McLeod, J. (2003). An introduction to counseling. Berkshire, England: Open University Press.

Meged, N. (1998). Gates of hope and gates of terror. Tel Aviv: Modan Publications. (Hebrew).

Moore, S. F., \& Myerhoff, B. G. (1997). Secular rituals: Forms and meanings. Assen: Van Gorcum.

Naor, D. (1999). A Journey in Nature in the footsteps of our soul. Unpublished masters thesis. Lesley College, Natania, Israel. (Hebrew).

Neill, J. T., and Heubeck, B. (1998). Adolescent coping styles and outdoor education: Searching for the mechanisms of change. In C. M. Itin (Ed.), Exploring the bound- 
aries of adventure therapy: International perspectives (pp. 227-243). Boulder, CO: Association of Experiential Education.

Orzek, A. (1987). Innovations in ecological psychology: Conversations with Roger and Louise Barker. Journal of Counseling and Environments, 65, 233-237.

Pendzik, S. (1994). The theatre stage and the sacred space. The Arts in Psychotherapy, $21,25-29$.

Pilisuk, M., \& Joy, M. (2001). Humanistic psychology and ecology. In K. J. Schneider, J.F.T. Bugental, \& J. F. Pierson (Eds.), Handbook of humanistic psychology (pp. 101-114). Thousand Oaks, CA: Sage.

Price, R., \& DeBever, M. (1998). The Windana therapeutic community's action adventure program. In C. M. Itin, (Ed.), Exploring the boundaries of adventure therapy: International perspectives. USA: Association of Experiential Education.

Richards, K., \& Smith, B. (Eds.). (2003). Therapy within adventure. Proceedings of the 2nd International Adventure Therapy Conference. Augsburg, Germany: Ziel Publications.

Richards, K., Peel, J.C.C., Smith, B., \& Owen, V. (2001). Adventure therapy and eating disorders: A feminist approach to research and practice. Cumbria: Brathay.

Ringer, M. (2003). Adventure therapy: A description. In K. Richards \& B. Smith (Eds.), Therapy within adventure (pp. 19-20). Augsburg, Germany: Ziel Publications.

Roberts, B., Horwood, S., Aunger, N., \& Wong, M. (1998). Adventure with adults living with psychiatry disability. In C. M. Itin (Ed.), Exploring the boundaries of adventure therapy: International perspectives. Boulder, CO: Association of Experiential Education.

Roszak, T. (2001). The voice of the earth. Grand Rapids, MI: Phanes Press.

Roszak, T., Gomes, M. E., \& Kanner, A. D. (1995). Ecopsychology: Restoring the mind, healing the earth. San Francisco, CA: Sierra Club Books.

Rubin, A. J. (1984). The art of art therapy. New York: Brumel Mazel.

Seed, J., Macy, J., Fleming, P., \& Naess, A. (1988). Thinking like a mountain. Philadelphia, PA: New Society Publishers.

Simpson, C. A., \& Gillis, L. (1998). Working with those who hurt others: Adventure therapy with juvenile sexual perpetrators. In C. M. Itin (Ed.), Exploring the boundaries of adventure therapy: International perspectives (pp. 318-331). Boulder, CO: Association of Experiential Education.

Taylor, E. (1992). Transpersonal psychology: Its several virtues. The Humanistic Psychologist, $20(2 \& 3), 285-300$.

Totton, N. (2003). The ecological self: Introducing eco-psychology. Counseling and Psychotherapy Journal, 14, 14-17.

Turner, V. (1967). The forest of symbols. London: Cornell University Press.

Turner, V. (1986). The anthropology of experience. Evanston, IL: Illinois University Press.

West, W. (2000). Psychotherapy \& spirituality: Crossing the line between therapy and religion. London: Sage.

West, W. (2004). Spiritual issues in therapy. New York: Palgrave.

White, M., \& Epston, D. (1990). Narrative means to therapeutic ends. New York: W. W. Norton.

Zimmerman, M. E. (summer 1989). Introduction to deep ecology. An Interview with Michael E. Zimmerman, by Alan AtKisson, Global Climate Change, (IC\#22), 24. 